\title{
POLÍTICA DE ASSISTÊNCIA SOCIAL E OS SERVIÇOS SOCIOASSISTENCIAIS PARA PESSOA IDOSA ${ }^{1}$
}

\author{
Luanne Maria da Costa Martins ${ }^{2}$ \\ Dalila Pereira Machado ${ }^{3}$ \\ Emanuelle Gomes dos Santos ${ }^{4}$ \\ Maria do Rosário de Fátima e Silva ${ }^{5}$ \\ Solange Maria Teixeira ${ }^{6}$ \\ Sthefany Francisca de Alencar Tito ${ }^{7}$ \\ Tamires Leticia Cardoso da Silva ${ }^{8}$
}

Resumo: Este trabalho tem como objetivo apresentar uma discussão teórica sobre a temática do envelhecimento, destacando suas múltiplas e complexas dimensões, destacando ainda, as principais políticas na área da assistência social e os serviços socioassistenciais voltadas para este mesmo público, abordando as tentativas de desmonte dessas conquistas no cenário contemporâneo brasileiro, com o avanço das reformas neoliberais.

Palavras-chave: Envelhecimento; Política de Assistência Social; Serviços socioassistenciais.

Abstract: This paper aims to present a theoretical discussion on the theme of aging, highlighting its multiple and complex dimensions, highlighting the main policies in the area of social assistance and social assistance services aimed at this same public, addressing attempts to dismantle of these achievements in the contemporary Brazilian scenario, with the advance of neoliberal reforms.

Keywords: Aging; Social Assistance Policy; Social assistance services.

\footnotetext{
1. Trabalho apresentado no Congresso Brasileiro Ciência e Sociedade (CBCS 2019), promovido pelo Centro Universitário Santo Agostinho, de 03 a 05 de outubro de 2019, em Teresina-PI.

${ }^{2}$ Graduanda em Serviço Social pela Universidade Federal do Piauí. Bolsista do Programa Institucional de Bolsas de Iniciação Científica - PIBIC. E-mail: luannemaria18@gmail.com

${ }^{3}$ Graduanda em Serviço Social pela Universidade Federal do Piauí. Voluntária do Programa Institucional de Bolsas de Iniciação Científica - PIBIC. E-mail: dalilamachado214@gmail.com

${ }^{4}$ Graduanda em Serviço Social pela Universidade Federal do Piauí. Bolsista do Programa Institucional de Bolsas de Iniciação Científica - PIBIC. E-mail: manu23690@gmail.com

${ }^{5}$ Doutora em Serviço Social pela PUC-SP. Professora do Programa de Pós-Graduação de Políticas Públicas da Universidade Federal do Piauí. E-mail: mrosariofat@hotmail.com

${ }^{6}$. Pós-Doutora em Serviço Social pela PUC-SP. Professora do Programa de Pós-Graduação de Políticas Públicas da Universidade do Piauí. E-mail: solangemteixeira@hotmail.com.

${ }^{7}$ Graduanda em Serviço Social pela Universidade Federal do Piauí. Bolsista do Programa Institucional de Bolsas de Iniciação Científica - PIBIC E-mail: sthefany.alencar@outlook.com

8 Graduanda em Serviço Social pela Universidade Federal do Piauí. Bolsista do Programa Institucional de Bolsas de Iniciação Científica - PIBIC. E-mail: cardoso.tamires.leticia@gmail.com
} 


\section{CONGRESSO BDîl EID

\section{INTRODUÇÃO}

O processo de envelhecimento, como uma temática de estudos vem sendo bastante discutido atualmente, em um cenário onde essa população etária cresce rapidamente e os países buscam, novas formas de proteção social e principalmente desenvolver novas formas de sistemas de aposentadorias, uma vez que as estatísticas apontam para cada vez mais um aumento na expectativa de vida das pessoas.

O envelhecimento pode ser compreendido como um processo biológico, mas também social, cultural e psicológico. Assim, é um fenômeno social universal que possui interligações com os âmbitos psicológico, social e econômico, ou seja, o modo como os seres humanos envelhecem e vivem a velhice é variada conforme suas condições de vida, trabalho, e a realidade de cada país, desenvolvimento destes e também as suas particularidades quanto ao tratamento dado as pessoas idosas.

Nesta perspectiva, deve ser considerada as inúmeras determinações que, marcam a vida de uma pessoa e como estas determinações impactam a longo prazo na velhice dela. Um determinante no que diz respeito às diferenças no modo de envelhecer são as divisões de classes e seus subgrupos ou frações, que se soma a outros demarcadores como o gênero, a raça/etnia, que demarcam situações de exploração e opressão na sociedade capitalista e são geradores de desigualdades sociais ao longo da trajetória de vida das pessoas.

O foco do estudo é a proteção social oferecida pela assistência social, com um mapeamento dos principais serviços socioassistenciais que se dirigem para a população idosa, especialmente os que dessa política necessitam. Analisando seu futuro numa conjuntura de desmonte acelerado das políticas sociais.

\section{METODOLOGIA}

Este artigo é resultante de um estudo teórico, com base na literatura e nos documentos da política de assistência social. Pretende ser arcabouço teórico de uma pesquisa maior que ainda prevê um estudo de campo, junto a profissionais que 


\title{
CONGRESSO BRASILEIRO

implementam os serviços socioassistenciais e pessoas idosas, no município de TeresinaPI.

\section{ENVELHECIMENTO: PROCESSO BIOPSICOSSOCIAL MARCADOS POR DIFERENÇAS, DESIGUALDADES E ELEMENTOS COMUNS}

Contemporaneamente, o tema envelhecimento vem sendo bastante pautado em todo o mundo. O Brasil é um país no qual a expectativa de vida tem aumentado, passando por transformações em sua pirâmide demográfica com o expresso envelhecimento populacional.

Dentre muitas definições de envelhecimento, temos esta que enuncia que

\begin{abstract}
O envelhecimento é um processo que pode ser compreendido como sequencial, individual, acumulativo, irreversível, universal, não patológico, de deterioração de um organismo maduro, próprio a todos os membros de uma espécie, de maneira que o tempo o torne menos capaz de fazer frente ao estresse do meio ambiente e, portanto, aumente sua possibilidade de morte. (ORGANIZACIÓN PANAMERICANA DE LA SALUD, 2003, p.30).
\end{abstract}

Pode-se perceber a prevalência de uma visão biológica do envelhecimento, ligada a decadência, sem fazer qualquer relação às condições de vida das pessoas, a sua realidade material que pode apressar, antecipar, ou retardar, conter seus efeitos, dentre outros. É verdade que a pessoa idosa passa por transformações naturais como perda de peso, as bochechas se enrugam, os cabelos ficam grisalhos, o nariz se alarga, há uma redução da mobilidade, o olfato e o paladar diminuem e entre outros, que são confundidos com as limitações dadas nessa faixa etária. Mas, não se discute que o ritmo desse processo, o modo como ele atinge as pessoas, as consequências que promove, os modos como se vivencia, experimenta e vive-se esse processo é variável.

O status da velhice é determinado socialmente; as velhices e o envelhecimento são plurais, mas com certas homogeneidades geradas pelas vivências comuns de vida. É para a classe trabalhadora, especialmente os mais pobres, que incide os estigmas, preconceitos e mitos. Sendo assim, a visão muito restrita e homogênea sobre esse processo impede compreendê-lo de uma forma ampla.

Outra limitação nas análises do envelhecimento é sua definição pela cronologia. Indubitavelmente quando se fala em envelhecer, majoritariamente é levado em conta 
somente uma das idades em que envolve a velhice, ou seja, a idade cronológica. Segundo Debert (2004, p.46),

[...] as idades cronológicas, baseados em um sistema de datação, estão ausentes na maioria das cidades não-ocidentais e são, nas cidades ocidentais, um mecanismo básico na atribuição de status (maioridade legal), de definições de papéis ocupacionais (entrada no mercado de trabalho), de formulações de demandas sócias (direito à aposentadoria).

Porém, é importante destacar que a cronologia não é determinante no modo de envelhecer, visto que o envelhecimento é um processo complexo no qual o ser humano vivência e que envolve na sua determinação processos múltiplos. No entanto, as outras idades desse processo, como a idade biológica, psicológica e social são vivenciadas de formas distintas por cada indivíduo, isto é, de maneira individual, mas também socialmente, reproduzindo desigualdades que distingue as condições de vida de cada um ou grupos de pessoas.

Isto posto, o processo de envelhecimento é heterogêneo, embora se tenha certas universalizações. É marcado por características intrínsecas de cada sujeito e de aspectos socioculturais como classe social, gênero, raça/etnia e questões de vivência na cidade ou no campo.

\footnotetext{
Tanto ao longo da história como hoje em dia, a luta de classes determina a maneira pela qual um homem é surpreendido pela velhice; um abismo separa o velho escravo e o velho eupátrida, um antigo operário que vive de pensão miserável e um Onassis. A diferenciação das velhices individuais tem ainda outras causas; saúde, família etc. Mas são duas categorias de velhos (uma extremamente vasta, e outra reduzida a uma pequena minoria) que a oposição entre explorados e exploradores cria. (BEAUVOIR, 1990, p.17)
}

Obviamente, por exemplo, o envelhecer de um idoso pobre é diferente do de um idoso rico, pois este tem mais condições para diminuir os impactos deletérios do envelhecimento, de tratar dos problemas de saúde mais prevalecentes, estão menos susceptíveis a abandono, maus-tratos, negligências e discriminações que embora aconteçam, todavia em menor grau. Estudos apontam que quanto maior for os níveis de vulnerabilidades (físicas, de renda, gênero, cor, idade, grau de dependência, dentre outros) de um ser, maiores são as probabilidades de experimento da violência, e quando se refere aos idosos, é de cunho doméstico e a maioria das vezes é cometida por seus próprios familiares. 
Ademais, reflexo das desigualdades sociais, e das oportunidades diferenciadas entre as classes, e seus subgrupos, está a nível educacional, grande parte dos idosos pobres não concluíram seus estudos, tendo uma baixa escolaridade. Assim como também o não acesso aos serviços de saúde de boa qualidade, às atividades de cultura e lazer, contribuindo para uma péssima qualidade de vida dessas pessoas. Outra questão a se destacar, é o fato de que a maioria desses idosos de baixa renda sustentam suas famílias com uma aposentadoria miserável, pois majoritariamente moram com seus filhos e netos, tendo que arcar com todas as despesas. Já para os idosos de condições financeiras melhores, o cenário é outro, a maioria tem acesso a planos de saúde, uma boa alimentação, uma boa escolaridade e assim deve-se ter ingressado em bons empregos (tendo uma boa aposentadoria), ou foram profissionais liberais autônomos, ou pequenos a grandes empresários, que tem como arcar com os custos de um envelhecimento ativo, saudável, com boa qualidade de vida.

Outro ponto a salientar, é o teor racial ou étnico e o envelhecimento, uma vez que tais temáticas estão interligadas entre si. Ao se falar em raça/etnia, "trata-se de uma importante dimensão da estratificação social que se relaciona de maneira complexa com a classe social, refletindo principalmente a distribuição de poder entre os grupos raciais no interior de uma dada sociedade" (BARATA,2009, p.58). Nesse viés, certamente, a posição que os indivíduos ocupam podem influenciar diretamente no nível de bem-estar deles, assim a população negra sofre grande desvantagem social frente aos demais. Os dados apontam menores níveis de acesso ao trabalho, educação, saúde, saneamento básico enfim, aos direitos sociais quando se comparado com os brancos. Se essas pessoas negras são também mulheres e pobres as desigualdades de acesso ao trabalho, os bens e serviços de uma sociedade são ainda maiores.

Dessa forma, todos esses aspectos influenciam no modo de envelhecer das pessoas de pele negra, e o não reconhecimento dessas desigualdades e desse racismo existente dificulta sua vida, e os impede de terem um envelhecimento ativo, saudável e prazeroso. Sob a ótica do gênero, tanto o homem quanto a mulher sofrem perdas, preconceitos e estereótipos, todavia as formas como enfrentam e vivem a velhice são distintas.

Conforme verifica-se, as relações de gênero, como construções sociais de dominação e subordinação, têm resultado, historicamente, em experiências e trajetórias diferenciadas para o homem e para a mulher, particularmente para as mulheres idosas de hoje, as quais vivenciaram a expectativa obrigatória de uma feminilidade marcada pela obediência, pelo conformismo e pelas desigualdades, além de uma apropriação social do seu corpo expresso no 
controle familiar e na medicalização das funções reprodutivas" (FERNANDES, 2009, p.419).

É notória que a trajetória da mulher sempre foi marcada pela desigualdade em relação ao homem, a submissão, a domesticidade, a dificuldade de ter uma formação e de acessar o mercado de trabalho, entre outros. Já os homens com mais "poder" e liberdade, com mais forte e variada parceria sexual, chefe e provedor da família. Assim, os homens velhos pobres da classe trabalhadora ficam mais "inaptos" para o trabalho, pois o sistema capitalista vê o idoso como improdutivo, excluindo-o do mercado de trabalho. Entretanto, para os idosos da classe dominante nunca estão inaptos para comandarem suas propriedades, empresas, grades negócios, para participarem da vida política, casarem-se novamente, viajar, projetos novos de vida, dentre outros. Já a mulher velha, para algumas é uma fase de libertação de certos controles societários; para outras, em uma sociedade que aprecia a juventude, isso acaba afetando a autoestima, sentem incomodadas com as marcas da velhice e recorrem a procedimentos estéticos (aquelas que possuem condições financeiras).

Por último, sobre a vivência no campo e na cidade, o envelhecimento nesses dois espaços é totalmente diferente. Os idosos da zona rural estão em mais desvantagens do que na zona urbana, pois vivem em uma realidade de pobreza, não tem maior acesso à educação e saúde de qualidade, vivem muitas vezes em condições precárias e isolados geograficamente.

Destarte, todas as questões supracitadas, elucidam que o envelhecimento é um processo biopsicossocial, complexo, heterogêneo, individual e grupal.

Os trabalhadores que compõem o exército dos excluídos, que tem condições de trabalho mais não são absorvidos, os informais, os autônomos em condições de precariedade, que foram repelidos do mercado formal de trabalho, embora contribuam para rebaixar o preço da força de trabalho empregada, com certeza, com uma trajetória incerta vai contribuir para acelerar as intempéries do envelhecimento, aparecimento de doenças agravadas pelas dificuldades no acesso aos serviços de saúde, à renda, à habitação digna vai repercutir no envelhecimento biológico e psicológico. Mas, será que as políticas sociais são pensadas para lidar com essas diferenças? 


\section{A PROTEÇÃO SOCIAL NO CAPITALISMO: PAPEL DAS POLÍTICAS SOCIAIS.}

O Modo de Produção Capitalista, é um processo revolucionário, caracterizado pelo desenvolvimento das forças produtivas ligado à expansão de grandes indústrias que acentuou a acumulação capitalista, tendo como gênese o continente europeu em meados do século XVIII. Mudam-se todas as formas de produção até então vigentes, e tem-se no centro de tudo isso, as consequências advindas deste mesmo processo, que são as expressões da questão social.

É nesse cenário de inquietações conflituosas por parte das classes sociais, na qual se tornaram protagonistas e constituíram suas identidades políticas, que o Estado passa a assumir o papel de principal disseminador de políticas sociais, que agem em resposta a estas mesmas expressões, gerando os chamados sistemas de proteção social que beneficiaram a classe trabalhadora, com acesso a segurança social.

Na realidade brasileira, cabe destacar que houve um processo de industrialização tardio em relação com outras nações, mas que a proteção social também esteve interligada com o processo de expansão do capital, para enfrentamento da pobreza extrema e manutenção do capital, através de políticas como trabalhistas, previdenciárias e assistenciais.

Vale ressaltar que esse processo de formação do sistema de proteção social brasileiro, avança com a CF/88 com base nos direitos sociais, justiça e equidade social. Mas, que sofre revés a partir de 1990 com as reformas neoliberais, tem uma trégua nos governos petistas e retornam com maior força, desde 2016, com a lógica da redução dos gastos sociais. É importante descartar que,

As despesas de manutenção da regulação do mercado colocam em crise, também, a política social. Mas a política social é uma estratégia política e econômica fato do qual decorre uma crise de legitimação política articulada à queda dos gastos na área social, já que o suporte dos benefícios e serviços sociais tornou-se decisivo para a vida cotidiana de milhões de famílias, e as políticas e os direitos sociais foram também uma conquista dos trabalhadores [...] (BEHRING ,2009, p. 21)

Essa lógica está em consonância com a lógica do capital, no seu modelo de acumulação flexível/financeirizado e neoliberal, e com as propostas de reformas que 
emergiram com o declínio do Welfare State. Assim, contribuindo para a implementação de políticas cada vez mais seletivas, focalizantes, que não atendem à demanda da população e não favorecem a autonomia do cidadão, principalmente daqueles em situação de vulnerabilidade social, que muito depende destas mesmas políticas.

Em relação à política de Assistência Social, dirigidas aos mais vulneráveis, a parcela da classe trabalhadora excluída das relações formais de trabalho, passa a ganhar mais ênfase a partir da implementação do Sistema Único de Assistência Social (SUAS) no ano de 2005. Desta maneira, a assistência social passa a organizar-se em um sistema descentralizado e também participativo, tendo como uma das principais finalidades, uma gestão compartilhada e financiamento das ações pelos três entes federados, com o controle social exercido pelos Conselhos de Assistência Social dos municípios, Estados e União.

Os serviços da assistência social no SUAS são organizadas em dois tipos de proteção: básica e especial, sendo esta última, subdividida em média e alta complexidade, com as medidas protetivas cabíveis em cada situação. Um dos princípios da proteção básica é "prestar os serviços de fortalecimento de vínculos, de pertencimento a família e a comunidade através do desenvolvimento de trabalhos em rede que garantam as profissões essenciais à sobrevivência e o acesso às demais políticas públicas" (PAIVA, 2013, p.98).

A Proteção Social Especial diferencia-se da básica por estar direcionada tanto às famílias, como também indivíduos que tiveram seus direitos violados. "Trata-se da proteção direcionada para indivíduos e grupos excluídos, o que não implica necessariamente na ausência de renda, apesar de que a pobreza pode se agravar a gerar condições de exclusão social [...].” (PAIVA, 2013, p. 99). A proteção social de alta complexidade envolve serviços dos quais possuem a finalidade de garantir a proteção de maneira integral a quem dele usufruir, podendo retirar dos seus núcleos familiares tais indivíduos, para instituições de acolhimento permanente ou provisoriamente.

A proteção social revela um capítulo importantíssimo na história da defesa e efetivação de direitos. Pensar uma sociedade mais justa, é conseguir enxergar suas inúmeras complexidades, e consequentemente, como os indivíduos estão atreladas à 
estas. A pessoa idosa carece de maiores cuidados por serem pessoas que necessitam de atenção, para não se tornarem somente uma massa de estatísticas. É preciso reconhecer que entre os idosos há diversas populações diferenciadas de pessoas idosas, com demandas diferenciadas que precisam ser atendidas.

\section{A PROTEÇÃO DA ASSISTÊNCIA SOCIAL NO BRASIL VOLTADA À PESSOA IDOSA}

O mapeamento dos serviços socioassistenciais dirigidos para as pessoas idosas de baixa renda, são:

\section{Quadro 1- Serviços da Proteção Básica:}

\begin{tabular}{|l|l|}
\hline NOME DO SERVIÇO: & PAIF (Serviço de Proteção e Atendimento Integral à Família) \\
\hline USUÁRIOS: & $\begin{array}{l}\text { - Famílias beneficiárias de programas de transferência de renda e benefícios } \\
\text { assistenciais e que atendem critérios de elegibilidade a tais programas e benefícios } \\
\text { ainda não contemplados; } \\
\text {-Famílias em situação de vulnerabilidade em decorrência de dificuldades vivenciadas } \\
\text { por algum de seus membros e também, pessoas com deficiência e/ou pessoas idosas } \\
\text { em situação de vulnerabilidade e risco social. }\end{array}$ \\
\hline OBJETIVOS: & $\begin{array}{l}\text { - Fortalecer a função protetiva da família; } \\
\text {-Prevenir a ruptura de vínculos familiares e comunitários; promover acesso a } \\
\text { benefícios, programas de transferência de renda e serviços socioassistenciais; } \\
\text { - Promover acesso aos demais serviços setoriais, e apoiar famílias que possuem, } \\
\text { dentre seus membros, indivíduos que necessitam de cuidados. }\end{array}$ \\
\hline
\end{tabular}

\begin{tabular}{|l|l|}
\hline NOME DO SERVIÇO: & Serviço de Convivência e Fortalecimento de Vínculos. \\
\hline \multirow{3}{*}{ USUÁRIOS: } & $\begin{array}{l}\text { - Idosos beneficiários do Benefício de Prestação Continuada } \\
\text { - Idosos de famílias beneficiárias de programas de transferência de renda } \\
\text { - Idosos com vivências de isolamento social por ausência de acesso a serviços e } \\
\text { oportunidades de convívio famílias e comunitário e cujas necessidades, interesses e } \\
\text { disponibilidade indiquem a inclusão no serviço. }\end{array}$ \\
\hline \multirow{3}{*}{ OBJETIVOS: } & $\begin{array}{l}\text {-Contribuir para o processo de envelhecimento ativo, saudável e autônomo; } \\
\text {-Assegurar espaço de encontro para os idosos e encontros intergeracionais de modo } \\
\text { a promover a sua convivência familiar e comunitária; } \\
\text {-Detectar necessidades e motivações e desenvolver potencialidades e capacidades } \\
\text { para novos projetos de vida; } \\
\text {-Propiciar vivências que valorizam as experiências e que estimulem e potencializem a } \\
\text { condição de escolher e decidir, contribuindo para o desenvolvimento da autonomia } \\
\text { e protagonismo social dos usuários. }\end{array}$ \\
\hline
\end{tabular}

\begin{tabular}{|l|l|}
\hline NOME DO SERVIÇO & $\begin{array}{l}\text { Serviço de Proteção Social Básica no Domicílio para Pessoas Com Deficiência e } \\
\text { Idosas }\end{array}$ \\
\hline USUÁRIOS & $\begin{array}{l}\text { Pessoas com deficiência e/ou pessoas idosas que vivenciam situação de } \\
\text { vulnerabilidade sócia pela fragilização e pela fragilização de vínculos familiares e }\end{array}$ \\
\hline
\end{tabular}




\begin{tabular}{|l|l|}
\hline & $\begin{array}{l}\text { sociais e/ou pela ausência de acesso a possibilidades de inserção, habilitação social } \\
\text { e comunitária. }\end{array}$ \\
\hline & -Prevenir agravos que possam desencadear rompimento de vínculos familiares e \\
sociais, & - Prevenir confinamento de idosos e/ou PCD's, identificar situações de \\
dependência. & - Colaborar com redes inclusivas no território \\
- Prevenir o abrigamento institucional com vistas a promover a sua inclusão social. & - Sensibilizar os grupos comunitários sobre direitos e necessidades de inclusão de \\
pessoas com deficiência e pessoas idosas buscando a desconstrução de mitos e \\
preconceitos; \\
OBJETIVOS \\
- Desenvolver estratégias para estimular e potencializar recursos das PCD's, e \\
pessoas idosas, de suas famílias e comunidade no processo de habilitação, \\
reabilitação e inclusão social; \\
- Oferecer as possibilidades de desenvolvimento de habilidades e potencialidades, \\
a defesa de direitos e o estímulo a participação cidadã; \\
-Incluir usuários e familiares no sistema de proteção social e serviços públicos, \\
conforme necessidades, inclusive pela indicação de acesso a benefícios e programas \\
de transferência de renda; \\
-Contribuir para resgatar e preservar a integridade e a melhoria de qualidade de \\
vida dos usuários; \\
-Contribuir para a construção de contextos inclusivos. \\
\end{tabular}

Fonte: elaboração das autoras com base em BRASIL (2009).

\section{Quadro 2: Serviços da Proteção Social de Média Complexidade}

\begin{tabular}{|l|l|}
\hline NOME DO SERVIÇO & $\begin{array}{l}\text { Serviço de Proteção Social Especial para Pessoas Com Deficiência, Idosas e suas } \\
\text { Famílias. }\end{array}$ \\
\hline USUÁRIOS & Pessoas com deficiência e idosas com dependência, seus cuidadores e família. \\
\hline \multirow{5}{*}{ OBJETIVOS } & $\begin{array}{l}\text {-Promover a autonomia e a melhoria da qualidade de vida de pessoa s com } \\
\text { deficiência e idosas com dependência, seus cuidadores e suas famílias; } \\
\text {-Desenvolver ações especializadas para superação das situações violadoras de } \\
\text { direitos que contribuem para intensificação da dependência; } \\
\text {-Prevenir o abortamento e a segurança dos usuários do serviço, assegurando o } \\
\text { direito à convivência familiar e comunitária; } \\
\text {-Promover acessos a benefícios, programa de transferência de renda e outros } \\
\text { serviços socioassistenciais, das demais políticas públicas setoriais é do Sistema de } \\
\text { Garantia de Direitos; } \\
\text {-Promover apoio às famílias na tarefa de cuidar, diminuindo a sua sobrecarga de } \\
\text { trabalho e utilizando meios de comunicar é cuidar que visem à autonomia dos } \\
\text { envolvidos e não somente cuidados de manutenção; } \\
\text {-Acompanhar o deslocamento, viabilizar o desenvolvimento do usuário e o acesso } \\
\text { a serviços básicos, tais como: bancos, mercados, farmácias, etc., conforme } \\
\text { necessidades; } \\
\text {-Prevenir situações de sobrecarga é desgaste de vínculos provenientes da relação } \\
\text { de prestação/demanda de cuidados permanentes/prolongados. }\end{array}$ \\
\hline
\end{tabular}

\begin{tabular}{|c|c|}
\hline NOME DO SERVIÇO & Serviço Especializado em Abordagem social \\
\hline USUÁRIOS & $\begin{array}{l}\text { Crianças, adolescentes, jovens, adultos, idosos e famílias que utilizam espaços } \\
\text { públicos como forma de moradia e/ou sobrevivência. }\end{array}$ \\
\hline OBJETIVOS & $\begin{array}{l}\text { - Construir o processo de saída das ruas e possibilitar condições de acesso a rede de } \\
\text { serviços e a benefícios assistenciais; } \\
\text {-Identificar famílias e indivíduos com direitos violados, a natureza das violações, as } \\
\text { condições em que vivem, etc. } \\
\text { - Promover ações de sensibilização para divulgação do trabalho realizado, direitos e } \\
\text { necessidades de inclusão social e estabelecimento de parcerias; }\end{array}$ \\
\hline
\end{tabular}




\begin{tabular}{|l|l|}
\hline NOME DO SERVIÇO & Serviço Especializado para Pessoas em Situação de Rua. \\
\hline USUÁRIOS & $\begin{array}{l}\text { Jovens, adultos, idosos e famílias que utilizam as ruas como espaço de moradia e/ou } \\
\text { sobrevivência. }\end{array}$ \\
\hline \multirow{3}{*}{ OBJETIVOS } & $\begin{array}{l}\text { - Possibilitar condições de acolhida na rede socioassistencial; } \\
\text {-Contribuir para a construção de novos projetos de vida, respeitando as escolhas dos } \\
\text { usuários e as especificidades do atendimento; } \\
\text {-Contribuir para restaurar e preservar a integridade e a autonomia da população em } \\
\\
\text { situação de rua; } \\
\text { - Promover ações para a reinserção familiar e/ou comunidade. }\end{array}$ \\
\hline
\end{tabular}

Fonte: elaboração das autoras com base em BRASIL (2009).

Quadro 3- Serviços da Proteção Social Especial de Alta Complexidade

\begin{tabular}{|l|l|}
\hline SERVIÇOS & Serviço de acolhimento institucional \\
\hline USUÁRIOS & Idosos \\
\hline \multirow{3}{*}{ OBJETIVOS } & $\begin{array}{l}\text { - Incentivar o desenvolvimento do protagonismo e de capacidades para a realização de } \\
\text { atividades; } \\
\text { - Desenvolver condições para a independência e o auto- cuidado; } \\
\text { - Promover o acesso à renda; } \\
\text { - Promover a convivência mista entre os residentes de diversos graus de dependência }\end{array}$ \\
\hline UNIDADE & $\begin{array}{l}\text { - Casa lar; } \\
\text { - Abrigo Institucional (Instituição de Longa Permanência para Idosos) }\end{array}$ \\
\hline
\end{tabular}

\begin{tabular}{|l|l|}
\hline NOME DO SERVIÇO & Serviço de Acolhimento em Repúblicas \\
\hline USUÁRIOS & $\begin{array}{l}\text { Idosos que tenham capacidade de gestão coletiva da moradia e condições de } \\
\text { desenvolver, de forma independente asa atividades da vida diária, mesmo que requeiram } \\
\text { o uso de equipamentos de autoajuda. }\end{array}$ \\
\hline OBJETIVOS & $\begin{array}{l}\text {-Proteger os usuários preservando suas condições de autonomia e independência; } \\
\text { - Preparar os usuários para alcance da autossustentação; } \\
\text { - Promover o restabelecimento de vínculos comunitários, familiares e/ou sociais. } \\
\text {-Promover o acesso à rede de políticas públicas. }\end{array}$ \\
\hline
\end{tabular}

Fonte: elaboração das autoras com base em BRASIL (2009).

Os quadros mostram que os serviços socioassistenciais dirigidos às pessoas idosas em situação de vulnerabilidade foram tipificados, normatizados e preveem proteção preventiva e, a especial em caso de violação de direitos. Um avanço para a sociedade brasileira, mas que ainda muito distante de se efetivar concretamente. A título de exemplo os serviços em domicílio ainda são raramente implementados pelos municípios brasileiros, assim como as repúblicas e outros, mostrando um hiato entre o normativo e a implementação.

\section{CONSIDERAÇÕES FINAIS}

Os serviços socioassistenciais, baseados nos critérios de equidade se dirigem para os mais vulneráveis, com vistas a reduzirem desigualdades sociais quando articuladas às políticas universais. O avanço do neoliberalismo ortodoxo no Brasil, pós 


\section{CONGRESSO BRASILEIRO

2016, tem deixado os pesquisadores com questionamentos sobre o futuro da proteção social capitalista. A política de redução de gastos públicos congelou o orçamento das políticas sociais por 20 anos. Nos anos de 2018 e 2019 o orçamento da política de Assistência Social sofrem cortes consideráveis, chegando a $50 \%$ do que era recebido antes em 2018. Assim, o caminho das políticas sociais no neoliberalismo tem sido focalização/seletividade, descentralização e privatização, o que nos leva a concluir que a assistência social não vai ser uma política universalizada, sendo seu destino a seletividade dos pobres dentre os mais pobres, deixando os vulneráveis a sua própria sorte ou infortúnio.

\section{REFERÊNCIAS}

BEAUVOIR, Simone. A velhice. Rio de Janeiro: Nova Fronteira, 1990.

BARATA, Rita Barradas. Como e por que as desigualdades sociais fazem mal a saúde. Rio de Janeiro: Editora Fiocruz, 2009.

BRASIL. Tipificação Nacional dos Serviços Socioassistenciais. Brasília: CNAS, 2009.

BEHRING, E. R. fundamentos de Política Social. In Ana Elizabete Mota... [ et al.], (Orgs). Serviço Social e Saúde: formação e Trabalho Profissional. 4 ed. São Paulo: Cortez; Brasília< DF: OPAS, OMS, Ministério da Saúde, 2009. p. 1-27.

DEBERT, Guita Grin. A reinvenção da velhice: socialização e processo de privatização do envelhecimento. 1.ed. 1. Reimpr. São Paulo: Editora da Universidade de São Paulo: Fapesp, 2004.

FERNANDES, M.G. Problematizando o corpo e a sexualidade de mulheres idosas: o olhar de gênero e geração. Revista de Enfermagem, Rio de Janeiro UERJ, p. 419, 17(3), 2009.

ORGANIZACIÓN PANAMERICANA DE LA SALUD. Guia Clínica para Atención Primaria a las Personas Mayores. 3. ed. Washington, DC, 2003.

PAIVA, Ariane Rego. A Consolidação de uma nova institucionalidade para a assistência social: o SUAS, seus avanços e desafios. In: (org.) João Bôsco Hora Góis: Questão Social e proteção social. Imo's Gráfica e Editora, Rio de Janeiro, 2013.

TEIXEIRA, S. M. Envelhecimento do trabalhador na sociedade capitalista I n:___ Envelhecimento na sociabilidade do capital. Campinas: Papel Social, 2017. 